\title{
Automated diverter valves at Kirkland Lake Gold Fosterville mine improve safety and efficiency
}

\author{
Russell Evans \\ Kirkland Lake Gold \\ Gary Trinker \\ Victaulic
}

SUMMARY: Traditional manual approaches to managing backfill systems are being replaced with improved and more efficient methods that are faster and safer. Automated diverter valves are among the technologies being used to effect efficiency and safety gains. Using diverter valves eliminates time-consuming manual operations that require special equipment and put workers in harm's way. A case study that assesses automated diverter valve operation and manual diversion at an Australian mine provides a comparison of functionality, time-savings, and safety advantages inherent to the diverter valve.

Keywords: Backfill Diverter Valve, Risk Reduction, Efficiency

\section{INTRODUCTION}

Many mine owners around the world are using manual backfill processes that rely on experienced workers investing considerable time and effort in risk-prone processes. These methods require significant manhours and are dependent upon having skilled laborers on site and expensive, specialized equipment on hand.

As mine owners employ different means of improving economics, many are using backfill systems to dispose of tailings and enhance ore recovery and are looking for safe and efficient ways to manage the backfill process. At Kirkland Lake Gold Fosterville mine in Victoria, Australia, automated diverter valves were installed at distribution switching points to improve this process, directing paste to the intended stopes without the need for underground crews and additional equipment.

Prior to the adoption of diverter valves, making changes in paste distribution was a manual operation that involved long sweep elbows to be disconnected from the piping network and reconnected to a different downstream pipe. This manual operation was time consuming, and when the necessary manpower and/or equipment was not available, resulted in considerable downtime.

The diverter valves address many of the issues encountered during manual operations. The valves function reliably in a broad temperature range, and valve operation does not require specialized equipment or skills. Because the valves can be operated remotely, they improve safety by reducing the risk of injury by removing people from harm's way.

This paper examines the use of automated diverter valves to replace manual diversion of paste in the Fosterville Gold Mine (FGM) reticulation system. Replacing the manual process with a remotely controlled system of valves resulted in dramatic reduction in safety risks and improved uptime by enabling safe and timely switching of the reticulation route. 


\subsection{Traditional approaches}

Most medium and high grade mining operations use backfill. The backfill is comprised of sand, tailings, aggregate and binders and can be abrasive resulting in wear on the system. When maintenance is required in the reticulation system or when backfill is required in a different stope the system is shutdown and manual switching of the piping is needed.

Each time this is required, multiple workers and equipment are involved and the resulting downtime is significant. In addition, this manual process introduces safety risks for the workers and takes them from more productive activities.

\subsection{Introducing innovation}

Victaulic designed the Series $725 \mathrm{~S}$ Diverter Valve specifically for use in backfill operations. Providing multidirectional service, the valve eliminates the need for manual manipulation of backfill piping systems.

Designed to withstand high pressures of underground systems, the valve is rated to 103.5 megapascals [MPa] (1500psi) and uses a 4D bend radius flow path to reduce wear from abrasive slurry and high-flow conditions. All wetted surfaces of the Series $725 \mathrm{~S}$ valve are constructed from martensitic stainless steel, which provides both excellent abrasion resistance and corrosion resistance. Continuous flushing is not necessary because the smooth profile of the plug prevents clogging. This valve is customizable, accommodating electric, hydraulic or pneumatic actuation, and can be installed vertically, horizontally or in any intermediate position. The valve is offered with either grooved, double grooved or ringed ends, allowing the specifier to choose their preferred mechanical couplings for quick and simple installation and removal.

Installing automated diverter valves at switching points on paste piping allows backfill to flow to alternative stopes without requiring manual manipulation of the pipe/pipe fittings to redirect flow.

\section{A NEW APPROACH}

Efficiency gains are being achieved by replacing manual backfill systems with methods that are faster and safer. Automated diverter valves are among the technologies being used to effect efficiency and safety gains. Using diverter valves eliminates time-consuming manual operations that require special equipment and introduce risks for workers.

Installing automated diverter valves in the Kirkland Lake Fosterville gold mine illustrates how functionality and safety can be improved, leading to time savings and ultimately better economics.

\subsection{Mine history}

The FGM is approximately $20 \mathrm{~km}$ east of the city of Bendigo and $130 \mathrm{~km}$ north of Melbourne in the State of Victoria, Australia. The FGM and associated infrastructure are on Mining License 5404, which is 100\% owned by Kirkland Lake Gold Ltd. (Figure 1).

Gold was discovered in the area in the mid-1800s, and mining activity was underway by 1894. Exploration activities by various owners of what is now the FMG ensued from 1973, with heap leaching operations from an oxide pit beginning in 1993. By 1998, Perseverance Corp., which operated the mine, was producing 40,000 oz/year from the oxide ore. In mid2001, a sulfide resource was developed, and an open pit was initiated in 2004. The first gold pour at the site took place in 2005.

The owners started an underground decline in March 2006, and the first underground stope was mined in December 2006. By early 2008, underground ore had become the main mill feed. The 500,000 th ounce of gold was produced in March 2011. Over the next seven years, the mine produced gold at a rate of $150,000 \mathrm{oz} /$ year. 

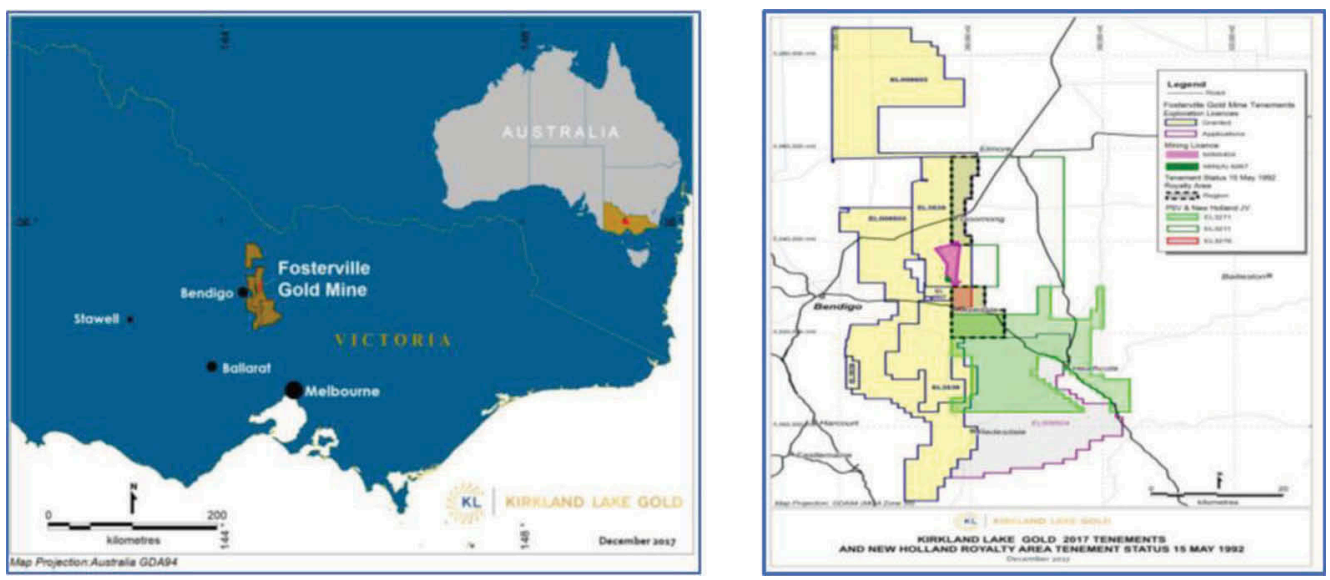

Figure 1. The Kirkland Lake Fosterville Gold Mine is approximately $20 \mathrm{~km}$ east of the city of Bendigo and $130 \mathrm{~km}$ north of Melbourne in the State of Victoria, Australia, on Mining License 5404.

Source: Kirkland Lake Gold, Toronto, Ontario.

Kirkland Lake Gold Ltd., headquartered in Canada, purchased the mine in November 2016 and began an aggressive exploration program that yielded impressive results, including the Swan Zone, which contains $2.34 \mathrm{M} \mathrm{oz}$ at an average grade of $49.6 \mathrm{~g} / \mathrm{t}$ gold. FGM produced approximately 600,000 ounces of gold in 2019 .

\subsection{Mining method}

Current mining at FGM is undertaken predominantly as owner-miner. FGM uses an open stoping, retreat mining method with the use of backfill to extract gold ore from the Phoenix decline ore bodies. Figure 2 shows the actual and proposed mining layout at FGM.

Stoping widths vary as dictated by grade distribution in the block model and strike length is determined by rock mass and hanging wall stability assessments. Once a stope has been mined out, the void is generally backfilled to ensure stability in accordance with planned future vertical and horizontal exposures. The open stopes are relatively small, ranging from $500 \mathrm{~m}^{3}$ to $2,700 \mathrm{~m}^{3}$ with an average of $1,500 \mathrm{~m}^{3}$. The current annual backfill requirement is $100,000 \mathrm{~m}^{3}$ to $110,000 \mathrm{~m}^{3}$ per year.

The selection of the specific mining method within the open stoping regime is based on previous experience at the Fosterville Mine and expectations of ore zone geometry and geotechnical conditions. A standard level interval of 20 vertical meters is usually applied across all mining areas. However, this can be varied to maximize the extraction of the economic material.

Underground mining is carried out using a conventional fleet, including twin boom development drills, production drills, loaders, trucks and ancillary equipment.

\subsection{Backfilling}

Historically, mining at FGM had been done top down without backfill or with limited quantities of cemented rock fill (CRF) using underground development waste mixed with cement slurry. With the discovery of the high-grade Swan Zone, a decision was made to design and construct a paste backfill system. In the interim, while awaiting the construction of the new paste plant, the stopes would all be filled with CRF. Because of the relatively flat dipping nature of the ore body, the hanging walls required topping up with flowable fill - a mixture of various sands, cement and water. The objective of this process was to reduce hanging wall failure. While it was effective, the backfill method was slow, and operating costs were high. 




Figure 2. Actual and proposed mining layout at the Kirkland Lake Fosterville Gold Mine.

Source: Kirkland Lake Gold, Toronto, Ontario.

The decision to switch to paste backfill was based on ensuring that the backfill achieved full confinement of hanging wall voids leading to higher productivity, lower dilution and reduced operating costs.

The plant process design combines full plant tailings and binder at a rate of $65 \mathrm{~m}^{3}$ per hour. The paste plant design includes a thickener and two large vacuum disc filters feeding a continuous mixer where binder and water are added to the filter cake to produce paste with the required slump or yield stress. Lime can also be added during this process.

The paste plant is located so the paste fill flows by gravity to the Phoenix ore zones. The paste is delivered through a $1,040 \mathrm{~m}$ borehole from the surface paste plant to the P4190L. The $75 / 8$ " steel casing in the borehole is lined with a $12 \mathrm{~mm}$ ceramic epoxy polymer coating. The borehole casing has an ID of $150 \mathrm{~mm}$. Figure 3 shows the paste reticulation long section at FGM.

\section{IMPLEMENTING AUTOMATION}

The current paste reticulation system is made up of 150NB Sch80 A106B SMLS pipe connected with Victaulic HP70ES couplings. The pipe lengths include exact $6 \mathrm{~m}, 3 \mathrm{~m}, 1 \mathrm{~m}$ and $300 \mathrm{~mm}$ straight lengths as well as Victaulic cast 3D bends of 90, 45, 22.5 and 11.25 degrees. The hanging and thrust support is galvanised steel.

The reticulation system instrumentation includes pressure sensors and flow meters as well as a dump valve at the bottom of the main borehole and pressure relief spools on each level. There are permanent closed circuit television (CCTV) cameras at two location on the P4190L. 


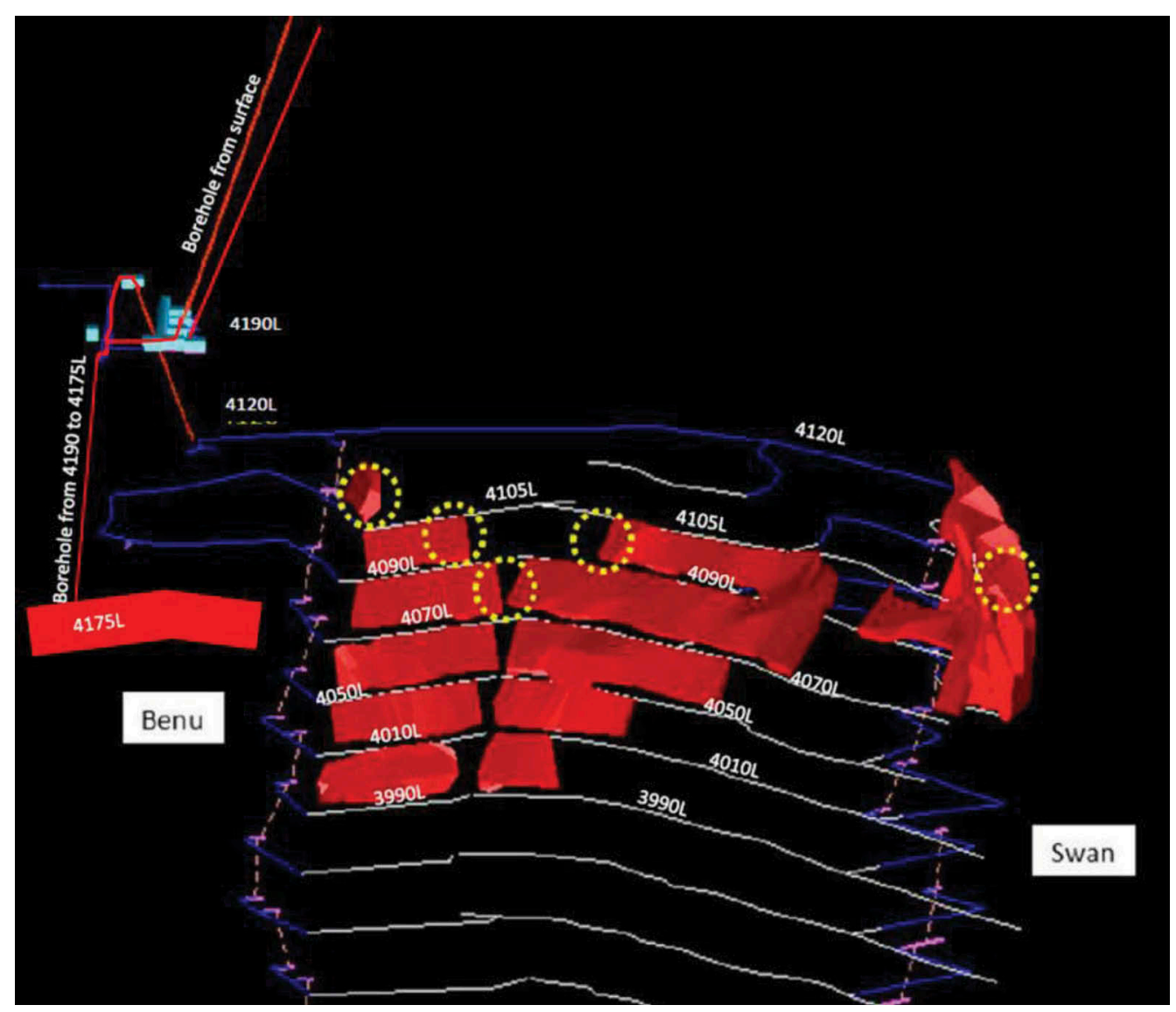

Figure 3. The Paste Reticulation Long Section at Fosterville Gold Mine.

Source: Kirkland Lake Gold, Toronto, Ontario.

Portable CCTV cameras are positioned at the pour point for each stope and at the fibrecrete bulkheads on the undercut of each stope. Total earth pressure cells and piezometers are installed inside most bulkheads. Workers monitor the instrumentation and CCTV cameras in real time from the control room at the paste plant.

A tradeoff study was done to evaluate the benefits of using actuated diverter valves versus manually changing the direction of pipe spools when switching the pour locations.

The relatively small stope volumes averaging only $1,500 \mathrm{~m}^{3}$ of paste was one of the factors that contributed to the decision to implement the use of diverter valves. Based on the stope volumes and the production rate of $65 \mathrm{~m}^{3}$ per hour, reticulation changes would be required at least once per day and possibly two times per day.

The decision was made to use remotely actuated diverter valves based on:

- Improved safety

- Higher productivity

- Lower operating costs.

The Victaulic 725S diverter valve was selected from among the various diverter valves available on the market based on design and price. 


\subsection{Fosterville diverter valve installation detail}

The Victaulic 725S diverter valves at FGM are equipped with $415 \mathrm{~V}$ electric actuators, limit switches and Auma remote control units. Pneumatic actuators and $240 \mathrm{~V}$ electric actuators were considered, but although pneumatic actuators could have reduced the capital cost, electric actuators were selected because electric power is required at the valve for the limit switches and solenoids and on each level for pressure sensors, flow meters and CCTV cameras. Underground power at FGM is $1,000 \mathrm{~V}$.

The underground instrumentation and diverter valves are controlled with a separate dedicated PLC and communications system. Rockwell Automation equipment was selected as this was the current standard at FGM. The surface Paste Reticulation Control Panel includes an Allen-Bradley ControlLogix 5571 PLC, FLEX I/O module and a Managed Ethernet switch.

This panel receives the inputs from the underground instrumentation and CCTV cameras and controls the diverter valves. This control panel communicates with the main Paste Plant PLC via ethernet which then enables the Paste Plant Operator to see the data from the instrumentation and control the diverter valves.

On each level underground there is a Form-4 Paste Board. These boards contain a $1000 \mathrm{~V}$ to $415 \mathrm{~V}$ transformer, a $1000 \mathrm{~V}$ to $240 \mathrm{~V}$ transformer, RT1100 Power Shield UPS and 24VDC power. These boards also contain FLEX I/O modules and ethernet switches.

The communication between the surface and underground control panels is through fiber optic cable. The fiber optic cable is connected to the ethernet switches in each panel and the FLEX I/O then connects the instruments and valves to the PLC.

Each diverter has a unique valve number in the PLC control logic, and each discrete paste line has a number. The inlet line and the A and B outlet lines from the diverter are numbered, with the numbers displayed on the valve as well as the underground pipes.

\subsection{Diverter valve operation}

The Paste Fill Note includes instruction for the setup of each diverter valve for each pour (Figure 4). The instructions indicate the required direction for each diverter using the diverter valve number and identifies the specified direction of flow to either the A or B outlet, including the paste line number for the outlet.

The Paste Fill Note is delivered to both the surface paste plant operator and the underground paste operator. The surface paste plant operator switches the valves to the required positions on the human machine interface (HMI) and advises the underground paste operator that the valves are in the correct position. The plant operator can see the route of the piping


Figure 4. The Paste Fill Note includes instruction for setting up each diverter valve for each pour. Source: Kirkland Lake Gold, Toronto, Ontario. 

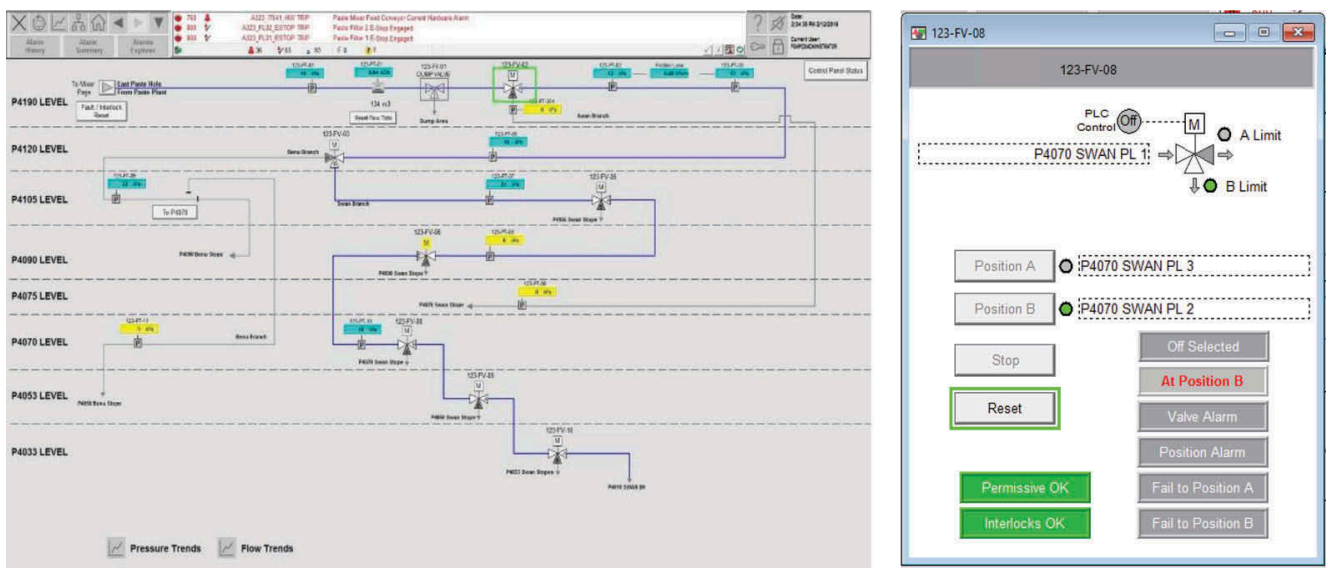

Figure 5. The plant operator can see the route of the piping highlighted in blue on the HMI display.

Source: Kirkland Lake Gold, Toronto, Ontario.

highlighted in blue on the HMI display. Once there is pressure or flow in the line, the colour changes from blue to red (Figure 5).

Using the Paste Fill Note, the underground paste operator checks all the pipes along the route to the stope, including the diverters. By consulting the diverter valve instruction in the note, the underground paste operator ensures the yellow indicator on the valve is pointing towards the correct line number indicated in the note. Once that has been confirmed, the underground operator switches the diverter control panel to the local mode so the direction of the valve cannot be changed during pouring.

\section{RESULTS}

Replacing the traditional manual approach to backfilling at FGM has enabled more streamlined operations, increased productivity, and reduced safety risks. The new process is allowing the mine to produce more ounces per day and is improving profitability.

\subsection{Higher productivity, reduced operating costs}

Once a stope is filled, the time required to change the piping location to the next stope is critical. In reticulation systems where there are no diverter valves, the steps required include traveling to the lockout location, performing the lockout (sometimes this takes place on the surface), traveling to the switching location, manually switching the pipe, and finally traveling back to the lockout location and removing the locks. This can take a team of three paste operators anywhere from two to five hours, depending on the layout of the mine and the lockout procedure in place. Using diverter valves eliminates these two- to five-hour delays, allowing paste filling to commence quickly. With the paste filling process expedited, mining can resume more rapidly, and ultimately, more ounces of gold can be mined each year.

Another benefit of this tremendous time savings is the substantial reduction of nonproductive time. Adopting an automated process means the diverters can be used during shift changes when there is no access to the underground. Automation also frees the paste operators to perform other work during time that otherwise would have been spent manually managing the paste fill process.

The cumulative effect is reduced operating costs. In a typical lower cost mine such as FGM, the total cost to purchase and install a single diverter valve can be repaid in less than one month through increased ore production. 


\subsection{Improved safety}

In addition to improving profitability, automated diverter valves improve safety. An inherent safety feature of the Victaulic $725 \mathrm{~S}$ Diverter Valve is that all moving components and primary seals are contained within the valve body (Figure 6). Other diverter valves that rely on exposed compression seals between the body and sliding plates or rotating discs, expose operations personnel to high pressure media spray and seal leakage if there is a failure during operation. In the unlikely event of seal wear on the Victaulic valve, all media remains contained within the valve body.

Because these valves can be actuated locally or from the surface control room, there is no need for a paste crew to travel to the valve location and work manually from the IT basket. Using these valves reduces the interaction of personnel and equipment and eliminates the risk of personal injury that is introduced every time a pipe switch is performed manually.

The local actuation feature on the Victaulic diverter valve is beneficial when work is required on the reticulation system. Every time paste operators need to work on the paste line, some form of lockout is required. The operator can travel to the level where the work is to be performed, change the diverter control unit to local actuation, switch the valve away from the line to be worked on and lock out the actuator to isolate the line. This functionality provides the highest level of safety for the paste operators working on the line because they can manage the process without relying on other personnel to ensure isolation, further reducing risk.

\subsection{Additional benefits}

The FGM reticulation system includes a dedicated dump valve on the P4190L so the contents of the surface borehole can be dumped into a dedicated sump in case of emergency. The

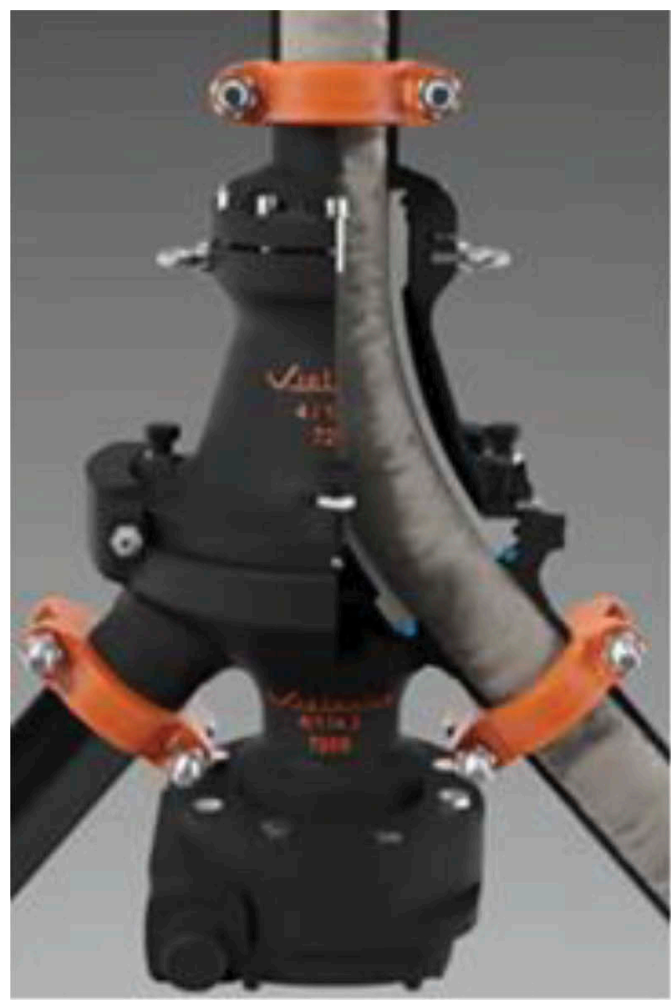

Figure 6. Series $725 \mathrm{~S}$ cross section.

Source: Victaulic Co, Easton, Pennsylvania. 
Victaulic $725 \mathrm{~S}$ diverter valve is rated for use as a dump valve under full pressure, so installing these valves on each level provides the additional benefit of being able to use the diverters for an emergency dump.

The cost of production delays caused by borehole blockages in mines varies depending on the production rate and the All-In Sustaining Costs (AISC) of the mine versus the current gold price. In broad terms, a month of lost production amounts to a few million dollars at most mines. Also, there are additional costs for clearing borehole blockages, (or in extreme cases total borehole replacement), which can exceed $\$ 1$ million. Therefore, a strategy of a reliable borehole dumping system and a backup surface borehole is used at most mines.

\section{CONCLUSIONS}

Replacing the traditional manual approach to backfilling at FGM has enabled more streamlined operations, increased productivity, and reduced safety risks. The new process is allowing the mine to produce more ounces per day and is improving profitability. The outlook for the FGM is positive, with continuing exploration success in the Harrier Zone and downdip in the Phoenix Zone. Expansion of the underground paste reticulation system to these areas will begin in 2020 and 2021. If the stope geometries are similar to those in the Swan Zone, the current diverter valve usage model will be implemented on these levels based on successes to date.

As backfill technology continues to develop and evolve, so will diverter valves. To meet the evolving needs of mine operators, valves containing multiple outlets for paste diversion, paste evacuation and flush water diversion, valves of higher-pressure ratings, valves of larger diameters, valves of more abrasion resistant materials, and valves capable of full automation and integration into intelligent systems are all conceived or being developed. 